\title{
Getting the best out of your students through cultural appreciation - multiculturalism in a 'British' university business classroom setting
}

\author{
Jon A. Wilson \\ Business School
}

\section{Introduction}

The following is a conceptual paper, reflecting on the author's own experiences whilst lecturing in marketing at London universities and, as a marketing professional. In addition, it provides current, supporting academic literature with the aim of stimulating further thinking and discussion. Finally, the paper offers suggestions for future activities that could be implemented in order to further address some of the issues raised.

There is an assertion that whilst multiculturalism has been embraced by British academic institutions and is actively encouraged, many of the day-to-day practices leave room for improvement. Within both education and industry, there appears to be a gap, whereby a potentially passive and sporadic transmission of multicultural values to the respective parties exists. This has lead to a suboptimisation of various learning experiences which have, in some instances, contributed towards a breakdown in communication; or, at their worst, resulted in a loss of confidence. It appears that this gap is more prevalent when interacting with individuals across cultures or in culturally diverse settings.

The position held is that an appreciation and active encouragement towards embracing multiculturalism, by both students and lecturers, is critical to the future long-term success of business education. The suggestion therefore is that lecturers should increase their efforts towards championing multiculturalism and embedding it within the formative aspects of their roles. A useful analogy would be one of a lecturer being like a conductor of an orchestra. To this end, it is hoped that this paper will be useful in its contribution towards a platform for both future empirical research and educational activities.

Culture appears to play a formative role in the educational process. However, the way in which culture impacts on a classroom setting, across nationalities, appears to differ. In support of this, Charlesworth (2008) asserts the following:

'If one accepts that culture is "a certain commonality of meaning, customs and rules (not a homogeneous entity) shared by a certain group of people and setting a complex framework for learning and development" (Trommsdorf and Dasen, 2001, p. 3004) then one cannot deny the connection between culture and learning... Furthermore systematic differences found in the way in 
which classrooms function in different parts of the world can be largely linked to cultural differences' (Crahay, 1996).

Having established this, there appear inherent differences and difficulties encountered when individuals from more than one culture enter the same educational setting. This paper attempts to reflect on these perceived gaps by reviewing existing literature and drawing from the author's own, personal experiences.

\section{Background}

Before writing this article, I sat down and collated a list of the various student nationalities that I could remember teaching last year. Normally at the start of a new course, as part of an ice breaker, I ask students to tell one another something about themselves. The reason offered being, that getting to know each other better, will benefit the whole class. After their name, the next piece of information usually provided is nationality or cultural ethnicity. Culture within the classroom is perceived by students as being:

- Appropriate to disclose

- Relevant to the course

- A significant defining factor of their own identity

- Something which would be of interest to the rest of the class.

Upon reviewing my notes, I was amazed by the fact that I had managed to reach a grand total of eighty separate or combined nationalities. It also became apparent that I could easily expect to encounter up to thirty different nationalities in any one class. In addition, within each country there are regional differences, mixed parentage family units, a host of different religious denominations and many other significant differentiating factors. These cultural phenomena are further compounded by the fact that we, as individuals, are increasingly complex in defining our own cultural identities as a result of our various interactions. Reflecting on these facts, my initial feelings were those of pride, quickly followed by a flood of questions:

- How did we all get along?

- Were the students as impressed by this fact as me?

- Did cultural ethnicity have any effect on the way in which we all interacted - and was it seen as a valuable experience by all, or a hindrance?

- How have we as lecturers changed, if at all, how we handle these situations?

- What could I do in the future to take advantage of these opportunities, both academically and commercially to the benefit the university?

- Is this cultural diversity so complex that it would be better to ignore it altogether in the classroom?

\section{Corporate culture and multiculturalism within business}

Taking my cue from industry, my feeling is that cultural diversity has to be both examined and actively used for competitive advantages no matter how difficult this is. The adage often quoted in business in connection with globalisation is, 'ignore it at your peril'. This caveat seems to suggest that managing culture, at the very least, could point towards it being a 'hygiene' factor - in that an 
improvement would remove dissatisfaction, but would not elicit positive motivation in itself (Hertzberg et al., 1959).

Before moving into education, my career had been in advertising. This grounding was one which seemed to revolve around the following mantras:

- Confidence is key and is built on good preparation and sound knowledge

- If you don't believe it, they won't!

- Communicate as often as you can, in as many ways as possible; but make sure you let them speak!

- Find a way to gather as much information as you can. No fact is too trivial!

- Build rapport and build up goodwill

- Handle objections and manage expectations at the earliest opportunity

- Do the simple things well, and then deliver the added value.

- Not everything that you hear is what they think

- Even a complaint can be converted into a buying signal and a happy customer

- Everything that you do has to have a gain, which is clear to all involved

- Make notes on everything!

Within this context, culture was generally restricted in its definition to being a management component, which both assumed and encouraged participants to create a universally, tenable, working environment. This being the case, cultural ethnicity seemed only to become of significance either if problems arose or if it presented a commercial gain. From this perspective, it could be argued that any explicitly derived knowledge and understanding may tend towards being superficial, sporadic, or at its worst exploitative. As a result, there tended to be individuals who championed cultural ethnicity and those who did not. In accepting this, it appeared to present uncoordinated or short-term benefits to only select parties. These thoughts brought my attention back to the starting point of this discussion. Namely, culture seems to be increasingly more significant and what can be done to address this issue?

Further to this, the most incisive and meaningful components of culture appear to be rooted in largely implicit drivers which can lead to complications. The utilisation of these truly valuable cultural traits, also hinges on the successful acquisition of tacit knowledge. Therefore a critical success actor rests in managing the transfer of this knowledge. Nonaka (1991), when looking at how tacit knowledge can be converted into the explicit, suggested that it is a process of 'finding a way to express the inexpressible', concluding that:

'Unfortunately, one of the most powerful management tools for doing so is frequently overlooked: the store of figurative language and symbolism that managers can draw from to articulate their intuitions and insight. At Japanese companies, this evocative and sometimes extremely poetic language figures especially prominently in product development.'

\section{Multiculturalism within business education}


As education draws upon both language and symbolism, it is felt that these sentiments can be carried through and applied to great effect. In addition, this would appear to be especially worthwhile when trying to decipher and cater for a diverse group of stakeholders in the interests of unification.

As a result of his analysis of Egyptian and UK senior managers in education, Humphreys (1996) suggested that systems from the Western world 'may need to be modified and adapted in order to fit the value, culture, expectations and practices of other, particularly developing countries.' As he said, 'It is perhaps a reflection of the possible complexity of such a task that produces the pragmatic but erroneous view that management principles are universal and therefore directly transferable to overseas projects.'

Whilst most students within university are not senior managers, they can be seen to have comparable traits. They have to undertake decision making and critical thinking as both individuals and in groups, which carry with them accountability and a formal assessment of their achievements. It would be reasonable therefore to assume that a significant proportion of students coming to the UK are likely to be unable to:

- Completely adapt, or suppress their preference for an educational environment similar to their host culture's, at least in part

- Fully take advantage of a British learning style without both willingness on their part and continual explicit support.

I have tried to draw from these collective experiences in my approach to education, in an attempt to formulate a unique selling point and measurable critical success factor.

\section{Cultural acclimatisation and orientation at university}

Whilst cultural diversity is reflected within student cohorts and academic material, a gap, or - at the very least - a difference of opinion, seems to exist in how affairs should be conducted within the classroom. A strong culture appears to prevail that, a British institution should pride itself on delivering a 'British' approach to education, providing a unique selling point. In addition, one could argue that we are in Britain and that is what students expect and desire (or at least should do?). Following this, a lecturer may find himself asking:

n How does this experience map to the consumer, in our case, the student?

- Can we do anything better?

- What needs to happen in the future?

I have had discussions and encountered points of view which have suggested that in countries like Italy, China and Saudi Arabia, amongst others, their styles tend towards 'rote learning' and compliance from students. This then begs the question, how do you guide someone through an alternative process, which rewards constructive debate, difference of opinion and honest, documented reflection - in a manner that has been termed as being distinctly British? And following this, once someone from another cultural frame of reference has become involved in this process, do they still feel at ease with, or even wish for, this type of environment? 
On paper, all students have successfully satisfied the entrance requirements for a course and so, in theory, should be well equipped to succeed equally. However, in practice, research, personal experiences and conversations with colleagues would suggest that there still appear to be noticeable differences, often sweepingly attributed to 'cultural differences'. What are the practical implications of all of this? After all, it seems that the wider public is engrossed in trying to answer the same underlying principles when looking to forge increased community cohesion. Following the same train of thought as stated by Nonaka (1991) previously, which points towards British culture, like any other, usually relying upon the implicit, tacit and inductive transition of the most valuable aspects of its cultural norms:

- What cultural aspects are significant in an educational setting?

- Which should be of significance?

- How does their implicit transmission occur?

- What remains tacit and who is party to this?

- Can these processes be improved and enjoyed by more?

- Can they be converted into more explicit methods?

These challenges seem to be compounded by the fact that at university, we trust that students have already acquired many of the softer skills associated with these processes. In addition, with such limited contact time, there are limitations on how much time can be devoted to these aspects. Therefore the onus lies on students to undertake much of this evaluation themselves. This requires self-regulation on their part, embarking on a journey of self-diagnosis, with taking the initiative to seek help when needed.

\section{The challenge of a $360^{\circ}$ appraisal of university culture}

Within business, companies are able to evaluate culture through audits. They attempt to draw from a mixture of hard and soft factors, which range from: a demonstration of associated financial gains, or cost saving, investors in people status, compliance with equality and diversity legislation, and stakeholder satisfaction, amongst others. However when it comes to evaluating the student experience, in connection with culture and ethnicity in education, there appear to be added challenges. There is not always a clear method by which its importance can be picked up, positioned or assessed. This could be due to the following factors:

- Human resources and marketing functions are largely involved in this process

- Human resources only cater for employees. Therefore, as students are not employees, they fall outside of their remit

- Marketing has little contact with students, once they have enrolled

- It becomes difficult to position students within this existing framework. Whilst students are perceived as being customers, their duty of care mainly transfers to lecturers; who are not involved in any formal cultural audit processes.

- The championing of cultural diversity is perhaps seen as being self-evident, in the reflection of the diverse backgrounds the students present.

One might also ask how is it possible to evaluate, not to mention reward, participants' championing of culture. After all, the same objectives could be met, without addressing these issues. Namely, the same course material is transmitted and students endeavour to attain the grades on offer. The initial 
terms of engagement focus on a university provide a degree course and a student meeting its various, academic requirements. Ownership of cultural ethnicity seems to remain the property of the individual and is secondary to subject content. The arguments posed in response to this are that cultural appreciation is:

- A 'hygiene factor' at the very least

- Or, more than a 'hygiene factor' - and therefore able to enrich the classroom environment

- Beneficial in having long term strategic gains

- Potentially able to reduce future problems; which may become a drain on university resources.

Therefore, this field necessitates a collective investment of time and effort, for what could be seen as a largely, but not exclusively, delayed gratification in spite of any difficulties faced.

\section{Diversity and equality for all?}

A further point of concern resides in the issues highlighted within a 54 page report compiled by the Equality Challenge Unit (2009), comprising a review of current literature and empirical data. It paints a less favourable picture, resulting from the views held by Black and Minority Ethnic (BME) professionals in higher education, in which a significant proportion of them state that they have experienced racism and/or racial discrimination. Mirroring this, the experiences of students seem to suggest that there is a 'growing gap in attainment between white, black and Asian students' (Shepherd, 2009). Furthermore, there also appears to be a 'disturbing racial divide among universities' (Curtis, 2006), with MacLeod (2009) reporting that in 2009, 'Just five students of black Caribbean origin started at Oxford this year; at Cambridge there are eight'. These comments suggest that the pull to address issues surrounding multiculturalism and the allocation of resources may not be comparable across institutions. Following this, with such scrutiny and media attention surrounding these issues, this subject is likely to generate added suspicion and perhaps a vote of no-confidence amongst some BME students and professionals - which can only be overcome through persistent efforts and increased resources over a longer timeframe.

\section{Culture, but at what cost?}

Crossley and Watson (2003, p35) highlight that educational institutions have become increasingly motivated primarily by financial objectives, when looking to research culture in connection with learning. Whilst this is a necessary activity, if it is at the expense of a more classical interpretation of the role of education, which has little to do with the pursuit of profits, it may pose serious long-term problems to an education institution by:

- Potentially prejudicing academic thinking

- Hampering the encouragement of free thought

- Failing to unearth meaningful insight into culture and learning, if they appear not to be financially profitable

- Going against the academic principle of understanding culture in connection with learning. In that it is a necessary part of ensuring the preservation of a pure transmission of knowledge. 


\section{Culture within the classroom}

Holden (2002) reviewed existing cross-cultural management and anthropological frameworks to suggest that managing across cultures is:

'the art of combining varieties of common knowledge through interactive translation. In order to develop this modified concept of cross-cultural management, it will be necessary to come to an understanding of translation both as a process and as an analogy' (p. 227).

Within this he appraised the role of language, concluding that it can be seen metaphorically with 'its symbolic powers serving to unite people with a sense of common purpose. Seen in this way, language is a very potent expression of company wisdom, lore and vision' (p. 236).

Sulkowski and Deakin (2009) assert that, "historically, education has taken the premise that all students are equally capable of learning regardless of ethnic background, social class or cultural origin'. However, their findings suggest that 'the question of why non-native students in the UK still seem to be underperforming becomes somewhat inconvenient'. They conclude that a solution to this problem is dependent on lecturers making students aware of their intellectual abilities and then developing them. Asmar (2005) supports this view by claiming that greater cultural understanding and sensitivity to differences are necessary pursuits for UK lecturers. However, Asmar goes on to state that this is hampered by some, due to perception that these students are a problem.

\section{Day-to-day practical experiences and approaches}

A cornerstone of my approach has been to champion cultural ethnicity within my subject material and classroom. Taking the lead from my experiences and training in advertising, I have reframed a student as oscillating somewhere between a key accounts client and a management trainee. Attempts to find out the backgrounds of my students and then match class material to their significant cultural frames of reference appear to have been well received. An essential part of this is being able to distil and crystallise both the similarities and differences between cultures and then map them to the subject wherever possible.

Our endeavours are eased by the fact that education in the UK is transmitted through one language, namely English. However, this should not be a premise for putting the onus on multi-lingual and culturally diverse students to conform completely to the norms of the English speaking lecturer. There should still be a continuous, collective appraisal of the more symbolic and metaphoric elements of language. In order to assist in the process, business thinking has borrowed from other disciplines such as psychotherapy and NLP (Neuro Linguistic Programming), e.g. Bandler and Grinder(1975).

I have also tried to address some of these issues by breaking down potential barriers and opposition, by selling the benefits of diversity and demonstrating as much in my behaviour. Within the classroom, I aim to make great efforts to pronounce peoples' names as they wish them to be pronounced, share anecdotes of my encounters with different cultures and have even tried to learn the odd phrase in different languages. This has had the effect of creating an environment of cultural curiosity, which I have then used to highlight and transmit the essentials and peculiarities of British 
academic culture, to hopefully fill gaps and impart significant elements that would assist students in their studies.

This approach draws strongly from methodologies present in social sciences and relationship marketing and services literature, suggesting that if benevolence is implicitly signalled with 'a caring attitude and personal commitment', the customer will reciprocate 'seeking repeated interactions and disclose information... if this seems natural' Hansen (2003). Students are increasingly being viewed as a customer of sorts, Baker (2008), Sellgren (2009). Whilst this remains contentious - especially from the perspective of a lecturer, as quality of delivery and service does not necessarily guarantee student satisfaction, it appears that students are becoming more and more comfortable with defining themselves as such.

The delivery of this customer orientation has posed challenges when orchestrating assessed group work activities. A common dilemma lies when addressing the question of whether it is more fruitful for students to work with people from the same cultural backgrounds, or whether to attempt to encourage them to work with people from different backgrounds. From both an academic and a long-term professional perspective the answer would have to be the latter. However, in the shortterm, with the pressures of students wanting to achieve good grades in as painless a way as possible, they may more often than not, opt for the former.

As a result, I have often put this question to students, presenting the merits of both sides. By empowering students to make an informed decision in this process, the aim has been to expose them to another facet of business whilst presenting a democratic and transparent process. This is designed to tie them into a psychological contract, which is also part of a process on my part to manage both their expectations and accountability through inclusion.

With more international students in the classroom, lecturing and providing business case examples, which all parties are able to understand and interpret to the same degree and in a comparable fashion, can present a challenge. This is especially problematic when setting more practical marketing assessments, which rely upon accessing current market data. For example; the nuances associated with broadsheet versus tabloid newspapers and their reliability; or the difference between commercial broadcasters and the BBC, in terms of carrying paid for advertising and product placement. This has necessitated my spending additional time introducing students to these marketing channels and at times, almost giving them a crash course on popular culture. This includes explanations surrounding slang and the fact that words like 'wicked' and 'sick' may have very different meanings, depending on the context. By contrast, within formal, academic writing there remains one acceptable interpretation. These facts are crucial, as in advertising, language is often reflective of its target audience. However, it is not always apparent to some students that this does not render such syntax and definitions acceptable for general academic usage.

The secondary effect from all of these collaborative activities is that through students' contributions, it is felt that their own cultural norms should permeate processes (Figure 1). The idea being that collaborative acculturation should set the agenda in harnessing diversity and preserving knowledge transfer. Without such appreciation and pro-activity, it is possible that the diversity of cultures would stagnate learning - plunging it into being passive shallow recall-based understanding. The long-term implications are that all parties involved, from the lecturer to the student, experience a hampered knowledge transfer and leave with less intellectual capital than could have been attained. 


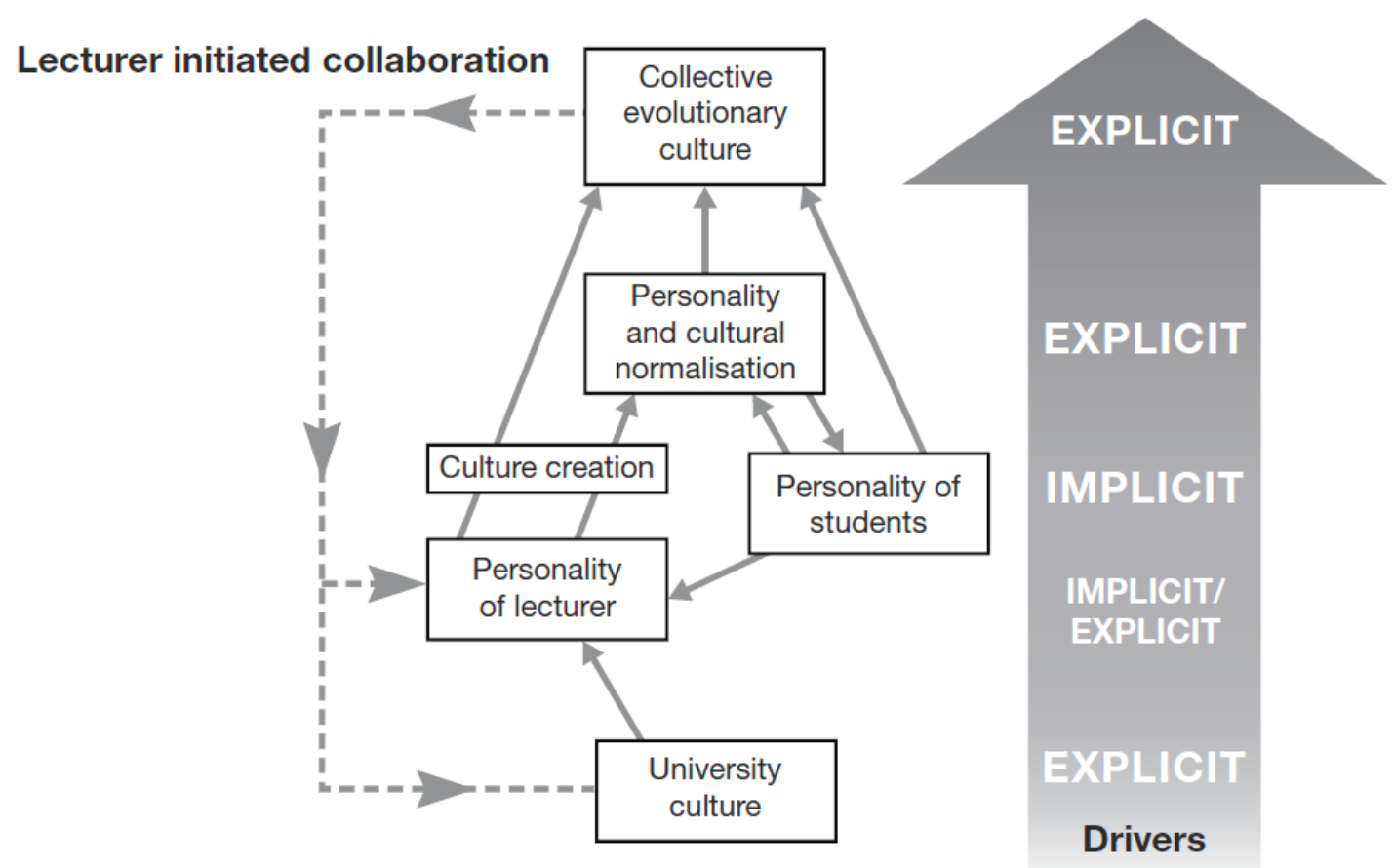

Figure 1: Collaborative acculturation - leading the agenda in harnessing diversity and preserving knowledge transfer.

\section{Conclusions}

Rowley (1996) states that 'most staff gain gratification from working with students and witnessing the achievement and development of those students. This is associated with having a professional pride in their work.' In addition, the view as stated in this paper asserts that lecturers should not overlook their own development and learning. The conclusions therefore are as follows:

- Lecturers should initiate, facilitate and control knowledge in the classroom

- Collectively, an environment should be created, in which two-way knowledge transfer can occur

- Cultural understanding is cited as being an active and essential component, when looking to appraise the successful execution of strategic objectives

- Culture has to play a role in the educational process and its normalisation and understanding can only occur when it is actively addressed and continually reviewed by all parties

- Culture, if competently and sincerely harnessed, has the potential with its associated trappings, to deliver academic and commercial gains

- Increased long-term gratification, attained from achievement and development, can be experienced by both students and lecturers through further developing meaningful relationships in which culture plays a part.

\section{Future agenda setting and suggestions}


Following the identification and acceptance of this approach, a more inclusive curriculum design could be achieved by a further allocation of resources. Workshops, discussions and empirical research should be conducted, in order to formalise a basis for action. In addition, involvement and knowledge transfer to the wider community is necessary in order to achieve a broad base of collective co-operation and normalisation. In this process, universities should attempt to liaise more closely with schools and industry, across geographic boundaries using the pursuit of an education in English, as a unifying factor. Many societies and those in the education and industry sector have signed up to this philosophy, though perhaps at times passively. However, what remains paramount is the continual pursuit of trying to address these issues by filling in any gaps practically. These require at their inception sound, value-based judgements and a conducive environment. Lecturers should see themselves as being central in this role, as they are both academics and the educators of future business people. A useful analogy is one of a lecturer being like a conductor of an orchestra. This is especially crucial as English is the lingua franca of business and an increasingly diverse audience of students arrives on British shores in their pursuit of excellence.

As a side point, universities in the United States and Australia have attempted to address some of these challenges, through offering a range of arts courses in non-connected disciplines. In addition, these courses have counted towards a student's final degree mark. It is not uncommon for business students to take courses in art appreciation, comparative religion or classical music, for example. This approach could be investigated and piloted initially, through offering non-assessed additional short courses. In order to encourage student attendance and participation these courses could be linked with:

- Opportunities to engage with industry

- Relevant internships

- Personal skills courses

- Career development workshops.

Ultimately, the fruits of these initiatives are our students. In what can be described increasingly as a commercial service-based industry, students are our customers, our ambassadors and our future academics. The focus therefore should be to manage this process in a manner which reflects their needs and those of industry.

\section{References}

Asmar, C. (2005) Culture and Pedagogy - International Comparisons in Primary Education. Oxford: Blackwell.

Baker, M. (2008) Students: Customers or learners?. BBC News Online, Education Section, Saturday 21 June 2008. Available at http://news.bbc.co.uk/1/hi/education/7466279.stm, (accessed 3 November 2009).

Bandler, R. and Grinder, J. (1975) The Structure of Magic I: A Book About Language and Therapy. Palo Alto, USA: Syntony Publishing.

Charlesworth, Z. M. (2008) Learning Styles Across Cultures: Suggestions for Educators. Education + Training, 50(2): 115-127. 
Crahay, M. (1996) L'Art et la Science de l'Enseignement. Bruxelles: Editions Labor. Crossley,

M. and Watson, K. (2003) Comparative and International Research in Education -

Globalisation, Context and Difference. London: Routledge Falmer.

Curtis, P. (2006) Segregation, 2006 style. Guardian.co.uk, Tuesday 3 January. Online. Available at www.guardian.co.uk/education/2006/jan/03/raceineducation.highereducation, (accessed 3 November 2009).

Equality Challenge Unit (2009) The Experience of Black and Minority Ethnic Staff Working in Higher Education. Online. Available at www.ecu.ac.uk/publications/experience-of-bme-staff-in-he, (accessed 3 November 2009).

Hansen, H. (2003) Antecedents to Consumers' Disclosing Intimacy with Service Employees. Journal of Services Marketing, 17(6).

Hertzberg, F. Mausner, B. and Snyderman, B.B. (1959) The Motivation to Work. New York: Wiley.

Holden, N. J. (2002) Cross-Cultural Management - A Knowledge Management Perspective. Harlow, Essex: Pearson Education Ltd.

Humphreys, M. (1996) Cultural Difference and its Effect on the Management of Technical Education. Leadership \& Organization Development Journal, 17(2): 34-41.

MacLeod, D. (2009) Oxbridge Universities Fail to Enrol Ethnic Minority Students.Guardian.co.uk, Thursday 12 March. Online. Available at www.guardian.co.uk/education/2009/mar/12/oxfordethnic-minority, (accessed 3 November 2009).

Nonaka, I. (1991) The Knowledge Creating Company. Harvard Business Review, Managing for the long term, July-Aug 2007.

Rowley, J. (1996) Motivation and Academic Staff in Higher Education. Quality Assurance in Education, 4(3): 11-16.

Sellgren, K. (2009) Mandelson Backs Consumer Students. BBC News Online, Tuesday 20 October. Online. Available at http://news.bbc.co.uk/1/hi/education/8316658.stm, (accessed 3 November 2009).

Shepherd, J. (2009) White Students do Better than their Asian and Black Peers, Study Finds. Guardian.co.uk, Tuesday 27 October. Online. Available at www.guardian.co.uk/education/2009/ oct/27/white-students-black-asian-gap, (accessed 3 November 2009).

Sulkowski, N. B. and Deakin, M. K. (2009) Does Understanding Culture Help Enhance Students' Learning Experience?, International Journal of Contemporary Hospitality Management, 21 (2): 154-166.

Trommsdorf, G. and Dasen, P.R. (2001) 'Cross-cultural Study of Education', in Smelser, N. and Bates, P., (eds.) International Encyclopedia of the Social and Behavioural Sciences, pp. 3003-7, Amsterdam: Elsevier. 